\title{
Factors Affecting the Attitude Toward Safe Sex and Reproductive Health Among Shiraz City Youth
}

\section{Farah AsnaAshari*‡}

\author{
Address: Tehran University, Tehran, Iran \\ Email: Farah AsnaAshari* - farahesnaashari@yahoo.com \\ * Corresponding author $\ddagger$ Presenting author
}

\author{
from 2005 International Meeting of The Institute of Human Virology \\ Baltimore, USA, 29 August - 2 September 2005 \\ Published: 8 December 2005 \\ Retrovirology 2005, 2(SuppI I):PI0 doi:I0.II86/I742-4690-2-SI-PI0
}

Owing to social and cultural taboos and inhibitions, sexual health research in Iran remains restricted to a few number of studies for youth, especially those who are unmarried. Social and cultural norms impose barriers to the transfer of sexual health information. Consequently, countless remain ignorant of even the basic knowledge required for safer sexual behavior. As this group requires having proper guidance regarding their health, which can make them beneficial for community and nation and so, they can play an innovative role for welfare and advancement of the country.

We want to have a clear idea of young adult's knowledge about reproductive health, safe sex, and STDs. Youth's attitude toward risky behaviour is an interesting topic that has attracted our attention. The main reason for this is that it focuses on youth in particular rather than the public. Youth are faced with numerous problems, which are sometimes beyond their comprehension. They may have heard of the phrase "Risky behaviours", but not everyone understands the meaning of these words. For the purpose of this research project, we have decided to limit the definition of risky behaviours to those practises that may lead to unsafe sex.

This is a quantitative study which will be done by the survey method. The major source of data in this study is a self-administerd questionnaire which will be used to collect data. There is a little difference between women and men questionnaires. Due to sensitive nature of some questions and to make the respondents feel at ease, female interviewers will be responsible for interviewing female respondents while the male interviewers will ask questions of male respondents. The assurance will be given to the committee representatives and respondents specially, the identification, names will not be made public or published, code numbers are given to their names. The questionnaire will be pretested to provide information on the clarity of the questions and respondents' comprehension. 